\title{
The Construction of WTO Framework for the Development of My Country's Information Technology Sports Industry Based on Big Data
}

\author{
Li Yuezhong ${ }^{1}$ and Liu Yichong ${ }^{1, *}$ \\ ${ }^{1}$ College of Physical Education and Health, Guangzhou University of Chinese Medicine, Guangzhou, China

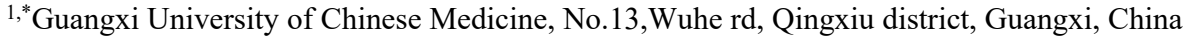

\begin{abstract}
With the improvement of China's economic level and the level of science and technology, people's demand for sports products and services is greatly increasing, and China's sports industry is showing a trend of diversified development. This article discusses the characteristics and connotations of the traditional sports industry and the characteristics of the sports industry in the era of big data, and then points out the challenges faced by the sports industry under the WTO framework and makes relevant recommendations. This paper also investigates the development status of the sports culture industry in our city through experiments, and the results show that the sports culture industry in our city involves 12 categories, of which sports film and television industry accounts for only $14.3 \%$.
\end{abstract}

\section{Introduction}

Big data technology promotes the development of modern information technology in our country. All walks of life are inseparable from modern information technology, and the sports industry is also deeply affected. The web live broadcast platform spawned by the Internet makes the audience of sports events wider, and the media broadcast of sports events meets people's spiritual needs and promotes the transformation of sports events. The sports industry has also emerged, including new sports industries such as e-sports, sports e-commerce, and fitness. The demand for sports products and sports services is also increasing. After joining the WTO, our country's sports industry has been pioneering and innovating, using modern science and technology, and the quality of various types of sports products has been continuously improving, which is more and more in line with people's sports needs [1].

Zhao J, He P and others made a comparative analysis of the sports policies and regulations of China and South Korea, and then compared the Chinese background and Seoul's sports industry's added value, the proportion of the sports industry in GDP, and the sports industry. The proportion of employees in the national population. Finally, it is concluded that the added value of China's Beijing sports industry is significantly lower than that of Seoul, South Korea [2]. Tu Y, Cao X, Zhang S and others pointed out that the lack of scientific and technological innovation ability is a factor restricting the development of China's sports industry. Therefore, they used cluster analysis to explore the technological innovation of China's sports industry, and the results showed that the data parameter index of sports industry technological innovation in 2007 is closer to the data parameter index of technological innovation in 2009 [3]. Sun R studied the development strategy of the rural sports industry based on the analytic hierarchy model. Analysis of the status quo of the development of rural sports in our country shows that the basic public service facilities for rural sports in our country account for $0.294 \%, 0.462 \%$, and $0.344 \%$ in sports, fitness sports facilities, and sports tips, respectively. Finally, it is pointed out that the real significance of physical education and national fitness for rural residents is still poorly understood, and the awareness of national fitness needs to be improved [4].

In today's economic globalization, China's sports industry is full of competition. There are competitions between different domestic cultural industries and international competitions in the sports industry. This article first introduces the connotation and characteristics of the painful sports industry, analyzes the characteristics of the sports industry in the era of big data, and then explains the challenges and countermeasures that our country's sports industry faces under the current social environment and international background, based on the WTO framework. China's sports industry is an important source of China's economy. For the high-speed and high-quality development of our country's economy, it is necessary to pay attention to the development of the sports industry. 


\section{The Construction of WTO Framework for The Development of My Country's Information Technology Sports Industry under Big Data}

\subsection{The Connotation and Characteristics of the Traditional Sports Industry}

The term "sports industry" is a term used in the market economy. Different scholars and experts have different definitions of the sports industry. Here, we adopt Professor Wu Chaolin's definition of the sports industry: sports activities and departments that provide society with directly competing sports products and services. The format of the sports industry refers to the types of commodities, organizational forms, business models, profit models, and management models provided by these sports activity organizations and departments. In terms of commodity types, the traditional sports industry mainly provides two types: sports services and sports goods. The service products of the traditional sports industry are not only sparse in variety, but the communication method between the service subject and the customer is single, and the understanding of the customer is relatively one-sided, which makes the service quality low. Substance commodities have low technology content and greater versatility. In terms of operation and management, the traditional sports industry lacks a reasonable production structure. For most companies, product production occupies the largest and most important part of the company, ignoring product innovation and research and development. In addition, most sports companies are learning from other industries and adopting common marketing methods in other industries. The marketing effects are average and the desired results cannot be achieved [5-6].

\subsection{Research on the Development of Sports Industry from the Perspective of Big Data}

\subsubsection{Characteristics of the sports industry under big data}

The event broadcasting industry no longer presents ownership; smart software and hardware products are becoming more and more diverse, such as smart jerseys, Xiaomi bracelets, and Xiaomi weight scales; sports e-commerce and e-sports have also reached unprecedented levels of development.

- Humanization and intelligence of product types.

In the era of big data, both Internet technology and modern information technology are developing vigorously. In this context, the personalization of sports products is becoming more and more comprehensive. The full application of the Internet provides businesses with more opportunities to understand consumers and can use Internet technology. The smart gym can track all the consumer's fitness records and the consumer's physical data. The system can generate targeted fitness programs based on these data for consumers to choose, and the sports service staff can instruct consumers to exercise scientifically and reasonably. With the development of software technology, there are more and more types of live events, social software, and service-oriented software, with more and more complete functions. These software satisfy people's daily social and entertainment, and at the same time cater to people's personalization in the era of big data. In the era of big data, intelligent sports products can generate different sports scenarios according to the different postures of consumers, provide consumers with more considerate services, and improve exercise levels and fitness effects [7-8].

- Diversified corporate organizational forms.

In the context of big data, the organizational forms of sports enterprises are showing diversified development. Nowadays, enterprises present different organizational forms such as listed companies and Sino-foreign joint ventures [9-10].

- Innovation of business management model.

The big data environment has given birth to a variety of high-tech products, and corporate management has also changed accordingly. In the face of such an environment, the sports industry is constantly pursuing innovation. This innovation is embodied in management methods and plans, and more embodied in management concepts, the management of individual talents, and the pursuit of integrated system management such as product management, marketing and market development. The current sports industry not only pursues the quantity of products, but also pays more attention to the functional innovation of products and the talent management brought to consumers. Enterprises have changed the traditional talent management methods, innovated the company's rules and regulations, and created a more scientific and standardized New era management model. The development of technology provides a broader platform for corporate marketing, expands the scope of marketing and increases consumer information channels.

\subsection{Challenges Faced by the Southeast Asian Sports Industry under the WTO Framework}

Since joining the WTO and successfully hosting the Olympic Games, under the impetus of modern information technology, the sports industry has gradually developed tremendously. With the development of the Internet and e-commerce industry, foreign sports products have always dominated China's high-end consumer market, such as Nike, Adidas, Prince, Reebok, and Security in the high-end parts of the domestic sports product market, while domestic brands like Li Ning The competitiveness of relatively well-known domestic brands such as, Huili and Anta is also at a weak point [11-12]. Since the Sino-US trade war, in 2021, ill-intentioned people will spread the rumors that China is squeezing cotton farmers and forced labor internationally. In late March, HM issued a statement to boycott Xinjiang cotton, and then Nike, Adidas and other brands also boycotted Xinjiang cotton. In the past, this trick may have been effective in curbing the growing 
economy, but China is no longer the China it used to be. After this incident, Chinese people also spontaneously refused to buy and use foreign brands that boycott Xinjiang cotton. Through the continuous enhancement of China's comprehensive national strength, China has already played an important role in the international economic market. The loss of the Chinese market means that the development of the brand will slow down. China's sports industry should seize this opportunity to improve the management performance of the company. Aiming at the quality of sports products and the improvement of the spiritual core, first seize the domestic market and create sports products with Chinese brands.

\subsection{The Countermeasures of My Country's Sports Industry under the WTO Framework}

Since joining the WTO, our country's market has been open. With the global emergency, the external environment of the sports industry and international market rules have become more complicated. This requires our country to seek new paths for the development of Chinese sports. Thinking, continuous learning, unity and hard work, overcome the negative impact of the environment, conform to the development needs of the times, and accelerate the innovative development of China's sports industry.

The current level of production in China is diversified and unbalanced. The development of the sports industry must intervene in government macro-control. The government must formulate corresponding policies to base sports industry investment on structural rationalization and institutional innovation, and focus on guiding the sports industry and combination of emerging industries.

Accelerate the training of talent teams in sports enterprises. Under the complex domestic and international forms, how the sports industry can bring in and go out requires high-quality sports management talents to make accurate judgments on international forms, and effectively use existing resources to enhance sports products and services in the domestic and international markets.

In the context of big data, modern information science and technology such as Internet technology and mobile communication technology are indispensable right-handed assistants for the development of the sports industry. Through the integration of new high-tech technologies with the sports industry, the scientific and technological content and level of the sports industry will be improved, the ability to transform scientific and technological research results will be strengthened, and the technological competitive advantage of China's sports industry will be created.

\section{Investigation and Experiment on the Development Status of Sports Culture Industry under the Background of Big Data}

\subsection{Experimental Content}

The sports industry is one of our country's economic sources. The advent of the era of big data makes the development of our country's sports industry present different characteristics. The key research object of this experiment is the development status of our city's sports culture industry. From the perspective of big data, we will conduct comprehensive development strategy thinking on the development of our city's sports culture industry.

\subsection{Experimental Process}

Based on the experimental research content, a network questionnaire was designed. After consent is obtained, the subjects of the questionnaire survey are leaders of sports-related enterprises in our city, leaders of the sports department of universities and employees in the sports industry. A total of 143 questionnaires were issued and 136 valid questionnaires were returned. The effective response rate of questionnaires reached $95.1 \%$. The collected questionnaires are collected and analyzed. In this process, the following formula is used:

Sample variance formula:

$$
\mathrm{s}^{2}=\frac{\sum_{\mathrm{i}=1}^{\mathrm{n}}\left(\mathrm{x}_{\mathrm{i}}-\overline{\mathrm{x}}\right)^{2}}{\mathrm{n}-1}
$$

Sample standard deviation formula:

$$
\mathrm{s}=\sqrt{\mathrm{s}^{2}}=\sqrt{\frac{\sum_{\mathrm{i}=1}^{\mathrm{n}\left(\mathrm{x}_{\mathrm{i}}-\overline{\mathrm{x}}\right)^{2}}}{\mathrm{n}-1}}
$$

\section{Analysis of the Survey Results of the Development Status of the Sports Culture Industry under the Background of Big Data}

\subsection{Analysis of the Status Quo of the Main Market Segments of the Sports Culture Industry}

Table1.List of Sports Culture Industry

\begin{tabular}{|c|c|c|c|}
\hline & Number & Percentage & $\%$ of cases \\
\hline Leisure & 7 & $8.6 \%$ & $100 \%$ \\
Sports & & & \\
Culture & & & \\
Festival \\
Industry & & & \\
\hline $\begin{array}{c}\text { Sports } \\
\text { Competition } \\
\text { Viewing } \\
\text { Industry }\end{array}$ & 7 & $8.6 \%$ & $100 \%$ \\
\hline $\begin{array}{c}\text { Sports Film } \\
\text { and } \\
\text { Television } \\
\text { Industry }\end{array}$ & 1 & $1.2 \%$ & $14.3 \%$ \\
\hline
\end{tabular}




\begin{tabular}{|c|c|c|c|}
\hline $\begin{array}{c}\text { Sports } \\
\text { (Online) } \\
\text { Game } \\
\text { Industry }\end{array}$ & 5 & $6.2 \%$ & $71.4 \%$ \\
\hline $\begin{array}{c}\text { Sports } \\
\text { News } \\
\text { Publishing } \\
\text { Industry }\end{array}$ & 7 & $8.6 \%$ & $100 \%$ \\
\hline $\begin{array}{c}\text { Sports } \\
\text { Culture } \\
\text { Tourism }\end{array}$ & 7 & $8.6 \%$ & $100 \%$ \\
\hline $\begin{array}{c}\text { Sports Folk } \\
\text { Cultural } \\
\text { Activities } \\
\text { Industry }\end{array}$ & 7 & $8.6 \%$ & $100 \%$ \\
\hline $\begin{array}{l}\text { Sports Art } \\
\text { Product } \\
\text { Industry }\end{array}$ & 7 & $8.6 \%$ & $100 \%$ \\
\hline $\begin{array}{c}\text { Sports } \\
\text { Advertising }\end{array}$ & 7 & $8.6 \%$ & $100 \%$ \\
\hline $\begin{array}{c}\text { Sports } \\
\text { Convention } \\
\text { and } \\
\text { Exhibition } \\
\text { Industry }\end{array}$ & 6 & $7.4 \%$ & $85.7 \%$ \\
\hline $\begin{array}{c}\text { Sports } \\
\text { Animation } \\
\text { Industry }\end{array}$ & 6 & $7.4 \%$ & $85.7 \%$ \\
\hline $\begin{array}{c}\text { Sports } \\
\text { Audiovisual } \\
\text { New Media } \\
\text { Industry }\end{array}$ & 7 & $8.6 \%$ & $100 \%$ \\
\hline Total & 81 & $100 \%$ & $1157.1 \%$ \\
\hline
\end{tabular}

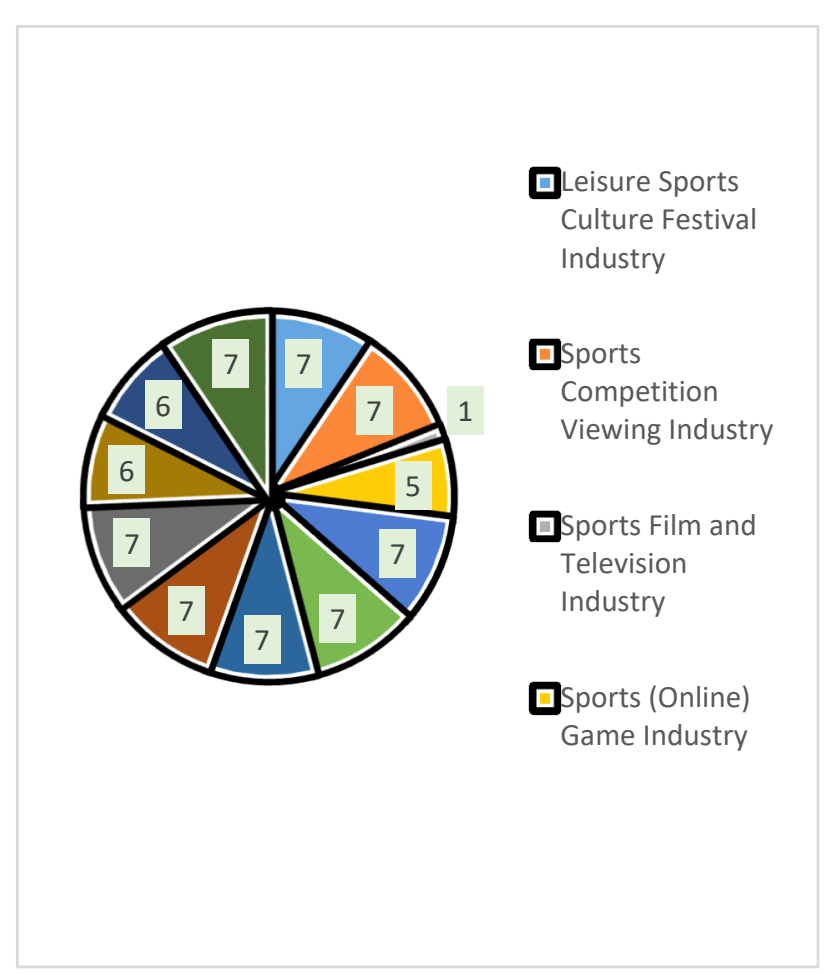

Figure1.Distribution of Sports Culture Industry

According to Table 1 and Figure 1, it can be seen that the leisure sports culture industry in our city involves a total of 12 industry categories. Among all the categories, the statistics obtained by the sports film and television industry are relatively small, accounting for only $14.3 \%$. Other industries Both exceed 70\%.

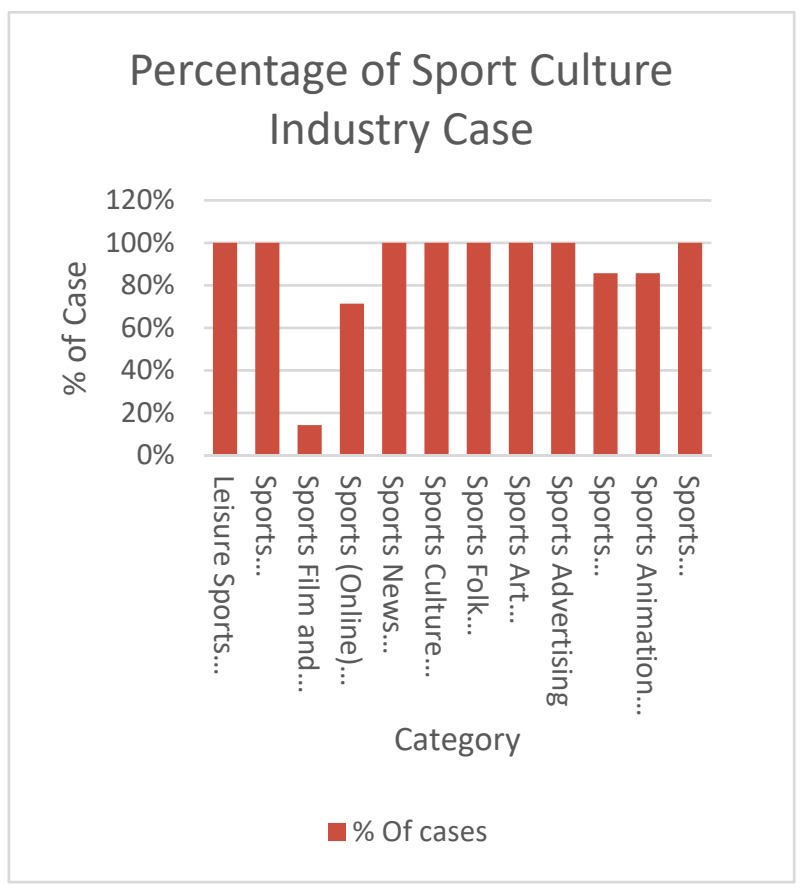

Figure2.Percentage of sports culture industry cases

According to the results of the questionnaire survey, it can be seen that the sports competition viewing industry, sports leisure cultural industry, sports folk cultural activities industry, leisure sports tourism, sports leisure cultural exhibition industry and other industries have a good development trend. The percentages are $100 \%, 85.7 \%, 71.4 \%, 100 \%$ and $100 \%$ respectively.

\section{Conclusions}

Big data has received widespread attention in recent years. It seems that all industries are discussing the innovation and changes caused by big data. As one of the sectors of the national economy, the sports industry has developed with the development of society. The sports industry under big data faces many challenges and opportunities. How to grasp these opportunities well is a problem that our country's sports industry needs to consider. Under the WTO framework, China's sports industry must seize the historical opportunity of the 2022 Winter Olympics, accelerate self-improvement, and ensure the introduction of excellent overseas sports industry services. At the same time, it must also do a good job in the sports industry with Chinese characteristics and promote the success of China's sports industry.

\section{References}

1. Wang Y, D Zeng. Development of sports industry under the influence of COVID-19 epidemic situation based on big data. Journal of Intelligent and Fuzzy Systems,39,6:8867-8875 (2020) 
2. Zhao J, He P. China and South Korea Two Countries Sports Policies and Regulations Development Comparative Analysis and Research. Journal of Computational and Theoretical Nanoscience, 13,12:9742-9745 (2016)

3. Tu Y, Cao X, Zhang S, et al. Fuzzy Clustering Analysis-Based Chinese Sports Industry Scientific and Technological Innovation's Study. Journal of Computational \& Theoretical Nanoscience, 13,12:9779-9782 (2016)

4. Sun R. New Urbanization Under the Background of China's Rural Sports Basic Public Service Supply Mechanism Innovation Research. Journal of Computational and Theoretical Nanoscience, 13,12:10170-10173 (2016)

5. Nishimura T, Endo M. Community Sports Club Manager Development Program. Journal of Japan Society of Sports Industry, 27,1:1_81-1_84 (2017)

6. Gordienko M S, Litvishko G V. Budget-Tax and Non-Tax Mechanisms in Sport Industry Development in the Russian Federation. Vestnik of the Plekhanov Russian University of Economics, 3:97-109 (2020)

7. Patel D, Shah D, Shah M. The Intertwine of Brain and Body: A Quantitative Analysis on How Big Data Influences the System of Sports. Annals of Data Science, 7,1:1-16 (2020)

8. Morgulev E, Azar O H, Lidor R. Sports analytics and the big-data era. International Journal of Data Science \& Analytics, 5,4:1-10 (2018)

9. Jiang C. Reforms and Challenges Faced by Sports Advertising Industry in the Era of Big Data. Study on China Physical Science, 2,3:145-152 (2020)

10. Assun Ca O R, Pelechrinis K. Sports Analytics in the Era of Big Data: Moving Toward the Next Frontier. Big Data,6,4:237-238 (2018)

11. Bagwell K, Bown C P, Staiger R W. Is the WTO Passé?. Journal of Economic Literature, 54,4:1125-1231(2016)

12. Feng L, Li Z, Swenson D L. Trade Policy Uncertainty and Exports: Evidence from China's WTO Accession. Journal of International Economics, 106, May:20-36(2017) 